THURSDAY, JULY $23, \quad 1885$

\section{A NEW DEPARTURE FOR THE UNIVERSITY OF LONDON}

$7 \mathrm{HE}$ influential movement which has grown out of the Educational Congress held during the Health Exhibition last year at South Kensington, and which has for its object the establishment of a Teaching University for London, has placed the existing University on the horns of a dilemma. Either it must be content to see itself altogether outdistanced by a new organisation which of necessity would absorb into itself all the teaching eminence of London, or it must rise to the occasion, and, bursting the cramped limits of its present contracted sphere of activity, show itself competent to the performance of larger duties.

The Convocation of the University, composed of the general body of graduates, has for its part shown at any rate a disposition to choose the latter alternative. After two successive debates it appointed a committee of forty of its members to see how far the proposals of the Association for a Teaching University could be carried into effect by the existing University. The report of the Committee has now been issued, and was printed by us in last week's NATURE. It will be submitted to an extraordinary meeting of Convocation to be held on Tuesday next.

What the action of the graduates will be it is of course impossible to predict with certainty. But it is hardly conceivable that, having assented to the principle of developing the University in the direction proposed by the Association, they will find much difficulty in accepting the scheme of reorganisation presented to them by Lord Justice Fry.

The scheme itself is necessarily cast in a somewhat technical form, and it is unaccompanied by any memorandum explanatory of its leading principles. These, however, it is not difficult to glean from it, and some account of them will, we think, be not without interest to many of our readers.

A priori the name of the University of London would call up to the mind of any one unfamiliar with the reality the image of a very splendid institution. This enormous city, which sooner or later absorbs into its life everything and everybody that rivets attention in the mind of the nation at large, might be expected to possess in its university a seat of learning where all the best of its intellectual activity would, as it were, be brought to a focus. That is the ideal. The reality is quite different. It is, in fact, a Government office which only by a kind of grim jest bears the name of a university. It is true it gives degrees; its graduates array themselves in gowns of surpassing brilliancy; it has a library and portraits of vice-chancellors; it has even a member of Parliament, But these are the mere accidents of its nature. Pierce below these insignificant academic symbols, and you find nothing but a mere State examination board supported by a Parliamentary grant; its expenditure controlled by the Treasury ; its accounts audited by the Audit Office ; and every academic regulation requiring the approval of the

VOL. XXXII.-No. 821
Home Secretary. Of any provision for the advancement and cultivation of knowledge there is none.

London however abounds with institutions of more or less eminence, in which studies of an academic kind are pursued. The first step which the Association saw to be necessary was to endeavour in some way to federate these. The task is one of no small difficulty. No educational establishment of any standing would care to sacrifice any portion of its autonomy, or to see taken from it any possible field of activity to which it might legitimately aspire. On the other hand, universal experience has shown that it is only those who are actually engaged in the higher kind of teaching who can be counted upon to supply the propulsive force needed for a real University activity. It is only those who work in the ultimate allotments of the fields of learning who can say how the achieved results in each area can be adapted to educational needs, and what help a University can give in securing harvests still ungrown and unreaped.

The leading feature of the scheme is-frankly following the principle on which the examining staff is secured-to bring into the University, irrespective of their previous connection with it, the best of the London teachers of University rank. These are to be obtained as representatives of Colleges who have agreed to come into the scheme. What these bodies sacrifice by so doing is scarcely appreciable. What they may gain may be very considerable. The teaching representatives so obtained (with some additional members) are to be grouped into four Faculties. In these Faculties the teaching arrangements of the several constituent Colleges may, though not necessarily, be brought into discussion. The result, it may be hoped, will be a better division by amicable arrangement of the higher educational appliances of the metropolis. And where (with the approval of the faculty) any particular constituent College undertakes the charge of some slenderly-supported branch of learning, it can hardly he doubted that the approval of the faculty will at least go a long way to securing public interest in the venture.

The faculties, then, can hardly fail to promote cooperation among the University teachers in London, and to better organise the attack on ignorance. But besides this they will enable the teaching bodies to gain for the first time a direct influence upon the examinations. Each Faculty will appoint a Board of Studies, and this will be charged with the duty of watching the examinations, keeping up something like a continuous tradition, and seeing that examination and teaching are in reasonable adjustment. Furthermore the Faculties will have direct representation on the Senate and that august body will in time be no longer a mere assemblage of notables holding their seats for life, but a real Academic Council for London at large, the members of which, being removable after a term of years, will always be in touch with their constituents.

These are the main outlines of the scheme. They appear to us to have been dexterously drawn between interference which the Colleges would resent and responsibility for their administration which the University could not accept. But though all this is admirable, it would not satisfy us if it were to be regarded as the final outcome of the scheme. Its great merit in our eyes is the 
provision we see in it for continuous development. The Faculties, the Boards of Studies, the Senate, are all under the scheme subject to provisions for renewing their composition. There will be therefore, we hope, a properly controlled flow of new life through every branch of the governing authority of the University. The present condition of crystalline rigidity will dissolve. As new objects of University enterprise come to the surface and assume definite shape, the men who advocate them will find their way to the Faculties and succeed in making their voices heard. At the same time there is sufficient opportunity for discussion to prevent the University being launched unadvisedly in any rash development.

We do not conceal our own hope that the most important outcome of the new scheme will be the ultimate provision of appliances for the prosecution of the higher studies in London. These never can be self-supporting, and never can, therefore, be properly undertaken by the constituent colleges. Ths voice of the faculties must be in the long run the voice of the men who compose them. That they will, therefore, if constituted, take some action in the matter, can scarcely be doubted. But instead of individual voices crying in the wilderness, there will be the mature utterances of a responsible body carefully guarding the intcrests of the constituent colleges on the one hand, and looking to the distinction and influence of the University on the other. Properly considered schemes will be put forward, and whether their execution devolves on the State, or is undertaken by private munificence, the public will for the first time have in the Faculties an authority competent to advise it in such matters, and whom it can listen to with confidence. The ultimate expansion of the University into all that can be desired, appears to us the inevitable outcome of Lord Justice Fry's scheme, if it is carried into effect.

\section{THE WOOL FIBRE}

The Structure of the Wool Fibre in its Relation to the Use of Wool for Technical Purposes. By F. H. Bowman, D.Sc., F.R.S.E., F.L.S., \&c. (Manchester : Palmer and Howe; London: Simpkin Marshall and Co., I 885 .)

THIS is a series of lectures delivered by Dr. Bowman to the students of the Bradford Technical College and the members of the Dyers' and Colourists' Society, and is in continuation of a similar series on the "Cotton Fibre."

The subject is one of so great importance that Dr. Bowman is amply justified in concluding that the information contained in his lectures ought to be accessible to others than students; for, if there is anything to learn with respect to a great national industry like the woollen trade, it is highly desirable that no time should be lost in communicating it to those who are now engaged in the trade, rather than that we should wait half a generation for the knowledge to become available in the hands of the students.

It is no doubt very difficult to introduce new methods and to banish old ones, except by the introduction of young blood; but even so, something may be done in the way of preparing the minds of the older workers to re- ceive the new ideas of the young ones, and this at least Dr. Bowman's work is likely to do.

Whether Dr. Bowman has been wise in preserving the lectures in their original form in his book we take leave to doubt. It makes the book very much larger than it would otherwise have been, owing to the unnecessary recapitulation at the commencement of each lecture, and not only so, but the labour and attention which would have been required to remodel the lectures would have prevented some glaring errors and defects of style which are by no means creditable to a writer of Dr. Bowman's attainments. A careful perusal of the proof-sheets would surely have removed such errors as "the appearance of the bulbous parts are very similar;" "the Exmoor sheep are the smallest of the two ;" and the vulgarism, "some of the sheep in the northern districts have four and even six horns, the same as the Iceland sheep."

These literary defects notwithstanding, the book is most opportune and valuable. The key-note of the whole is perhaps to be found in the following sentence :- "All our machines and processes are only a means to an end, and the correct mcthod of proceeding is ever to have the end in view from the beginning. Strange as this may appear, such is not always the case in our manufactures, and especially in those where the materials pass through many hands in different works before reaching the final stage. How often do we find the farmer, for example, quite careless in regard to the nature of the dips, and washes, and smears which he uses for his sheep, in utter forgetfulness of the fact that, although he may gain a temporary advantage, he is spoiling the wool for future use in spinning and dyeing."

Dr. Bowman puts forcibly before his readers the fact that wool is a part of the skin of the animal on which it grows, and is capable of being modified to a very great extent indeed-much more than most people are aware-by change of climate, food, and other surroundings, and especially by judicious breeding. One-sixth of the book is devoted to an enumeration of the various breeds of sheep to be found in the world, for the purpose of illustrating this. Perhaps, if we may be permitted to say so, this division of the work might have been judiciously shortened by the omission of details respecting numerous breeds of sheep which are now of little more than historical importance, especially as Dr. Bowman appears to be of opinion that the course which has been followed is the right one, and that we are now in possession of practically the best breeds of sheep which we could have for wool-producing purposes.

The lectures are five in number, of which the first is chiefly introductory. In it the author discusses the difference in composition and structure of animal and vegetable fibres and minutely describes the structure of cotton, silk, and wool as disclosed by the microscope. He points out the distinction between hair and wool so far as any real difference exists, and describes the constitution of the skin and the mode of production and growth of hair or wool.

The second lecture is chiefly devoted to a description of the various breeds of sheep and of the results of crossbreeding.

In the third lecture the author describes the typical structure of wool fibre under the two heads: $(a)$ in regard 